\title{
Microvascular decompression is an effective therapy for trigeminal neuralgia due to dolichoectatic basilar artery compression: case reports and literature review
}

\author{
Apra Caroline $^{1} \cdot$ Lefaucheur Jean-Pascal $^{2} \cdot$ Le Guérinel Caroline ${ }^{3}$
}

Keywords Microsurgical decompression · Janetta · Vertebrobasilar dolichoectasia $\cdot$ Trigeminal neuralgia $\cdot$ Brain MRI

\section{Introduction}

Essential trigeminal neuralgia due to vasculonervous conflict is a frequent painful disorder with an incidence rate of five for 100,000 people per year $[1,2]$. They most commonly involve the superior cerebellar artery, in $75 \%$ of cases, the anterior inferior cerebellar artery, in $10 \%$, or a vein, in $7 \%$ [3]. However, compressions by vertebrobasilar artery dolichoectasia are rare, ranging from 2 to $2.4 \%$ of cases in most studies (cf. Table 1). In our hospital, among 215 consecutive patients treated for trigeminal neuralgia, only three presented vertebrobasilar dolichoectasia (1.4\%).

\section{Apra Caroline}

caroline.apra@neurochirurgie.fr

Lefaucheur Jean-Pascal

jean-pascal.lefaucheur@aphp.fr

Le Guérinel Caroline

caroline.le-guerinel@hmn.aphp.fr

1 Centre Hospitalier Universitaire Henri Mondor, Assistance Publique Hôpitaux de Paris, Créteil, France

2 Service de Neurochirurgie, Centre Hospitalier Universitaire Henri Mondor, 51 avenue du Maréchal de Lattre de Tassigny 94010 CRETEIL cedex, Créteil, France

3 Service de Physiologie Explorations Fonctionnelles, Centre Hospitalier Universitaire Henri Mondor, Assistance Publique Hôpitaux de Paris, Créteil, France
Although first-line treatment is medical, involving carbamazepine or other anticonvulsants, trigeminal neuralgia is widely treated by microsurgical decompression of the nerve [21]. We noticed that, in daily practice, surgery is less frequently proposed when a dolichoectatic vertebrobasilar artery is involved, because of technical complexity and possibly higher complication rate.

We report three cases of patients who underwent microsurgical decompression for trigeminal neuralgia secondary to compression by a basilar artery dolichoectasia, review all published cases, and discuss the main aspects of these specific cases.

\section{Case reports and technical microsurgical description}

Case 1 A 59-year-old man had a two-year history of rightsided facial pain, affecting mainly the maxillary territory (V2) and radiating to the mandibular (V3) territory. The episodes were described as very intense and triggered by touching the right lip or shaving. After 6 months of interruption, the pain reappeared stronger. Patient's past medical history included sleep apnea syndrome and appendectomy. Dental examination was normal, as well as neurological examination and routine blood tests (basic metabolic panel and complete blood count). Pain was relieved by a treatment combining carbamazepine (400 mg per day), baclofen (30 mg per day), gabapentin (1200 mg per day), and paracetamol (4 g per day). However, pain resumed every time the treatment was reduced. Transcutaneous electrical nerve stimulation had a partial and limited efficacy over time. Brain magnetic resonance imaging (MRI) showed dolichoectatic right vertebral and basilar arteries. The basilar artery compressed the fifth nerve at the trigeminal root entry zone (TREZ) and its proximal segment from the inside.

Surgical decompression was proposed because medication was poorly tolerated. A right retrosigmoid approach was performed with cerebellopontine angle and trigeminal nerve 
Table 1 Cases of trigeminal neuralgia secondary to compression by a dolichoectatic vertebrobasilar artery [4, 5, 6-19]

\begin{tabular}{|c|c|c|c|c|c|c|c|c|}
\hline \multicolumn{2}{|l|}{ Reference } & $\begin{array}{l}\text { Number of cases } \\
\text { (vertebral/basilar artery) }\end{array}$ & Prevalence & \multicolumn{2}{|c|}{$\begin{array}{l}\text { Associated nerve } \\
\text { compressions }\end{array}$} & \multicolumn{2}{|c|}{$\begin{array}{l}\text { Neurological signs } \\
\text { associated with neuralgia }\end{array}$} & $\operatorname{Sex}(M / F)$ \\
\hline Miyazaki, 1987 [17] & \multicolumn{2}{|c|}{$45(0 / 45)$} & $7.7 \%$ & \multicolumn{2}{|l|}{ None } & \multicolumn{2}{|l|}{ None } & $2 / 3$ \\
\hline Harsh, 1991 [11] & \multirow{2}{*}{\multicolumn{2}{|c|}{$\begin{array}{l}1 \\
31(19 / 12)\end{array}$}} & NR & \multicolumn{2}{|c|}{ AICA-facial nerve } & \multicolumn{2}{|l|}{ Facial spasm } & NR \\
\hline Linskey, 1994 [4] & & & $2.0 \%$ & & \multicolumn{2}{|c|}{$5(16 \%)$ facial spasms } & $21 / 10$ \\
\hline Garcia de Sola, 2001 [8] & \multicolumn{2}{|c|}{3} & NR & NR & & \multicolumn{2}{|l|}{ NR } & NR \\
\hline Kraemer, 2006 [13] & \multicolumn{2}{|c|}{1} & NR & \multicolumn{2}{|l|}{ None } & \multicolumn{2}{|l|}{ None } & $1 / 0$ \\
\hline Goel, 2009 [9] & \multicolumn{2}{|c|}{$1(0 / 1)$} & NR & \multicolumn{2}{|l|}{ None } & \multicolumn{2}{|c|}{ Fusion of cervical vertebrae } & $0 / 1$ \\
\hline Noma, 2009 [18] & \multicolumn{2}{|c|}{$3(2 / 1)$} & NR & \multicolumn{2}{|l|}{ None } & \multicolumn{2}{|l|}{ NR } & $2 / 1$ \\
\hline Alcala-Cerra, 2011 [6] & \multicolumn{2}{|c|}{1} & NR & \multicolumn{2}{|c|}{ Brainstem compression } & \multicolumn{2}{|l|}{ None } & $1 / 0$ \\
\hline Campos, 2012 [20] & \multicolumn{2}{|c|}{1} & NR & \multicolumn{2}{|l|}{ None } & None & & $1 / 0$ \\
\hline Gressot, 2012 [10] & & & NR & NR & & Spasm & & $1 / 0$ \\
\hline Lin, 2012 [15] & 3 & & NR & 1 & & NR & & $1 / 2$ \\
\hline Park, 2012 [5] & & 3/7) & $2.0 \%$ & NR & & NR & & $14 / 6$ \\
\hline Yang, 2012 [19] & & & $2.1 \%$ & 8 & & NR & & $5 / 5$ \\
\hline Ishii, 2013 [12] & & & NR & IV nerve $\mathrm{c}$ & ompression & None & & $1 / 0$ \\
\hline Ma, 2013 [16] & & & $2.4 \%$ & NR & & $\begin{array}{l}2 \text { facial spas } \\
\text { loss; } 1 \text { hy }\end{array}$ & $\begin{array}{l}\text { ns; } 1 \text { hearing } \\
\text { oesthesia }\end{array}$ & $8 / 3$ \\
\hline Our cases, 2016 & & & $1.4 \%$ & 0 & & 1 facial hype & rsensitivity & $3 / 0$ \\
\hline Reference & $\begin{array}{l}\text { Mean } \\
\text { age }\end{array}$ & $\begin{array}{l}\text { Trigeminal } \\
\text { division } \\
\text { and side }\end{array}$ & $\begin{array}{l}\text { Treatment (MD: } \\
\text { microvascular } \\
\text { decompression) }\end{array}$ & & Treatment & acy & Complication & \\
\hline Miyazaki, 1987 [17] & 64 & 23 left-sided (51\%) & NR & & NR & & NR & \\
\hline Harsh, 1991 [11] & NR & NR & 1 partial rhizotomy & MD & $100 \%$ pain- & mmediately & NR & \\
\hline Linskey, 1994 [4] & 60 & 20 left-sided (65\%) & $\begin{array}{l}29 \mathrm{MD} ; 1 \text { complete } \\
1 \text { partial rhizotor }\end{array}$ & $\begin{array}{l}\text { zotomy; } \\
+ \text { MD }\end{array}$ & $\begin{array}{l}100 \% \text { pain- } \\
86 \% \text { pain } \\
\text { tion } \\
\text { after } 10 \mathrm{y}\end{array}$ & $\begin{array}{l}\text { mmediately; } \\
\text { off medica- }\end{array}$ & $\begin{array}{c}13 \text { hypoesthes } \\
\text { diplopia; } 4\end{array}$ & $\begin{array}{l}\text { ransient } \\
\text { g loss }\end{array}$ \\
\hline Garcia de Sola, 2001 [8] & NR & NR & $3 \mathrm{MD}$ & & $100 \%$ pain- & mmediately & NR & \\
\hline Kraemer, 2006 [13] & 63 & Left-sided V2 + V3 & $1 \mathrm{MD}$ & & $100 \%$ pain- & mmediately & $\begin{array}{l}\text { Mild and rev } \\
\text { desequilib }\end{array}$ & \\
\hline Goel, 2009 [9] & 65 & Left-sided V2 + V3 & $\begin{array}{l}1 \text { foramen magnum } \\
\text { decompression }\end{array}$ & & $\begin{array}{l}100 \% \text { pain- } \\
\text { after } 18\end{array}$ & $\begin{array}{l}\mathrm{ff} \text { medication } \\
\mathrm{s}\end{array}$ & None & \\
\hline Noma, 2009 [18] & 66 & 3 right-sided V3 & $1 \mathrm{MD} ; 2$ thermoco & ations & $100 \%$ pain- & mmediately & $\begin{array}{l}1 \text { paresthesias; } \\
\text { impairment } \\
\text { controlatera }\end{array}$ & aring \\
\hline Alcala-Cerra, 2011 [6] & NR & Left-sided & $1 \mathrm{MD}$ & & $\begin{array}{l}100 \% \text { pain- } \\
\text { after } 9 \text { ye }\end{array}$ & ecurrence & None & \\
\hline Campos, 2012 [20] & 63 & $\begin{array}{l}\text { Right-sided V2 + } \\
\text { V3 }\end{array}$ & $1 \mathrm{MD}$ & & NR & & NR & \\
\hline Gressot, 2012 [10] & 66 & NR & $1 \mathrm{MD}$ & & $100 \%$ pain- & mmediately & NR & \\
\hline Lin, 2012 [15] & 73 & 3 left-sided V2 + V3 & Microvascular susp & & $\begin{array}{l}100 \% \text { pain- } \\
\text { after } 16 t\end{array}$ & $\begin{array}{l}\text { ff medication } \\
\text { weeks }\end{array}$ & 1 hypoesthesia & \\
\hline Park, 2012 [5] & 74 & $\begin{array}{c}5 \mathrm{~V} 2+\mathrm{V} 3-8 \mathrm{~V} 2-3 \\
\mathrm{~V} 3-4 \mathrm{~V} 1+ \\
\mathrm{V} 2-4 \\
\mathrm{~V} 1+\mathrm{V} 2+\mathrm{V} 3\end{array}$ & 20 Gamma knife & & $75 \%$ pain-fr & mediately & 2 numbness & \\
\hline Yang, 2012 [19] & 64 & 5/10 left-sided & $10 \mathrm{MD}$ & & $\begin{array}{r}100 \% \text { pain- } \\
\text { after } 3 \text { to }\end{array}$ & $\begin{array}{l}\text { ff medication } \\
\text { onths }\end{array}$ & 1 numbness & \\
\hline Ishii, 2013 [12] & 77 & Left-sided & Electrical neurocoa & ation & $\begin{array}{r}\text { Pain-free of } \\
18 \text { montl }\end{array}$ & lication after & Transient diplc & \\
\hline Ma, 2013 [16] & 63 & 8 left-sided (73\%) & $\begin{array}{l}9 \mathrm{MD} ; 2 \text { selective } \\
\text { nerve rhizotomy }\end{array}$ & $\begin{array}{l}\text { al posterior } \\
\text { MD }\end{array}$ & $\begin{array}{l}100 \% \text { pain- } \\
\text { after } 221\end{array}$ & $\begin{array}{l}\text { ff medication } \\
\text { s }\end{array}$ & $\begin{array}{r}3 \text { facial numbr } \\
\text { palsy; } 1 \text { fac }\end{array}$ & $\begin{array}{l}\text { facial } \\
\text { asm }\end{array}$ \\
\hline Our cases, 2016 & 63 & $\begin{array}{l}1 \text { left-sided, } 1 \text { V2, } 1 \\
\text { V2 + V3, } 1 \text { V1 + } \\
\text { V2 + V3 }\end{array}$ & $3 \mathrm{MD}$ & & $\begin{array}{r}100 \% \text { pain- } \\
\text { at } 24 \mathrm{mo}\end{array}$ & ff medication & $\begin{array}{l}2 \text { transient dip } \\
\text { facial numb }\end{array}$ & $\begin{array}{l}1 \text { transient } \\
1 \text { mild ataxia }\end{array}$ \\
\hline
\end{tabular}

$N R$ not reported

exposure. Arachnoid dissection revealed the basilar artery compressing the right anterolateral region of brainstem and the TREZ. Microvascular decompression was performed by placing pieces of Dacron and Teflon between the artery and 
nervous structures. The basilar artery left an imprint on trigeminal nerve, which corresponds to a grade III compression according to Sindou et al. [1].

Immediately after surgery, pain attacks resolved completely. Moderate right facial palsy was observed and recovered completely on day 4 . Right abducens palsy without diplopia was observed and partially resolved on day 4 . No other adverse events occurred. During hospital stay, high blood pressure was discovered and treated. The patient was discharged on day 4 after surgery.

Seven weeks after surgery, the patient was seen in consultation and had still no pain, despite the halving of its drug treatment. The right sixth and seventh nerves palsies had resolved completely. Numbness of the right upper lip and the right side of the tongue was found on neurological examination, although the patient had not noticed it. There was no hearing loss, dizziness, other neurological sign, or cerebrospinal fluid (CSF) leak. Medication was completely and definitively stopped within the four following weeks without any pain recurrence after 2 years.

Case 2 A 74-year-old man had an 8-month history of right facial pain affecting the maxillary branch (V2) of trigeminal nerve. Episodes of pain were triggered by touching the right nasolabial sulcus or mastication. Patient's past medical history included bilateral presbycusis and high blood pressure. Neurological examination was normal. Treatment based on carbamazepine (750 mg per day) was efficacious, but poorly tolerated (drowsiness). Brain MRI showed a dolichoectatic basilar artery compressing the right fifth nerve at the TREZ. The right superior cerebellar artery also pressed on the proximal portion of fifth nerve.

Surgical decompression was proposed because medication was poorly tolerated. A right retrosigmoid approach was performed, and arachnoid dissection revealed the dolichoectatic basilar artery compressing the brainstem and the right TREZ and the superior cerebellar artery compressing the trigeminal nerve proximally. First, the superior cerebellar artery was separated from the fifth nerve by placing pieces of Teflon. Secondly, brainstem decompression was performed by placing pieces of Dacron and Teflon between the basilar artery and the brainstem. The vascular compression left an imprint on trigeminal nerve, which corresponds to a grade III compression according to Sindou [1]. Abducens nerve had to be manipulated during the surgery to gain access to the compression site.

Trigeminal neuralgia resolved completely after surgery, including both pain attacks and permanent discomfort. Neurological examination showed right sixth nerve palsy with diplopia, which was treated by a short course of steroids starting at $100 \mathrm{mg}$ per day, together with orthoptics. No other adverse event occurred. The patient was discharged on day 6 after surgery.
Six weeks after surgery, the patient had still no pain, despite analgesic medication completely stopped. Diplopia improved but he developed mild vertigo, which was managed by vestibular rehabilitation, persisting after 9 months. There was no hearing loss, hypoesthesia, facial palsy, other neurological sign, or CSF leak. The pain did not recur after 2 years.

Case 3 A 57-year-old man with no past medical history presented with a 14-year history of left-sided trigeminal neuralgia. He was treated with carbamazepine ( $400 \mathrm{mg}$ per day) and clonazepam, without complete pain relief. Preoperative clinical examination revealed isolated left facial hypersensitivity. Brain MRI showed voluminous bilateral vertebral arteries with a basilar dolichoectasia compressing the left TREZ and trigeminal nerve. Surgical decompression was proposed because medication did not relieve the pain.

A left retrosigmoid approach was performed, revealing the right vertebral artery and the dolichoectatic basilar artery compressing the brainstem and the left TREZ, alongside with the left superior cerebellar artery compressing the trigeminal nerve more distally. Both conflicts were released by pieces of Dacron and Teflon. The vascular compression left an imprint on trigeminal nerve. Surgical approach is shown in Fig. 1.

Trigeminal neuralgia and facial hypersensitivity resolved completely after surgery. The patient presented parotiditis which was treated with antibiotics, and there was no adverse effect of surgery. He was discharged on day 7.

Six weeks after surgery, the patient had no more neuralgia, he was still taking carbamazepine and clonazepam, which were stopped progressively, and neurological examination was completely normal. The pain did not recur after 1 year.

\section{Discussion}

\section{Population}

Overall, essential trigeminal neuralgia concerns $64 \%$ females of mean age 67 with past history of hypertension [22]. Regarding trigeminal nerve compression by a vertebrobasilar artery dolichoectasia, literature data show that patients are rather males, 66-years old in average, and often hypertensive. This is probably because male sex, aging, and hypertension are risk factors for developing dolichoectatic vessels [4]. The review of the 143 previously published cases is presented in Table 1.

Overall, $62 \%$ of trigeminal nerve compression by a vessel are right-sided $[1,22]$. On the opposite, compressions by dolichoectatic vertebrobasilar arteries are more frequent on the left side $(63 \%)$. The left-sided predominance may be explained by the fact that the left vertebral artery is dominant in most patients, as first described by Meckel and confirmed by vascular imaging $[2,23,24]$. Therefore, because of this 
Fig. 1 Surgical approach of case 3. a Axial 3D-FIESTA MRI showing the conflict between a dolichoectatic basilar artery (long arrow) and the left trigeminal nerve (short arrow). b, c, d Peroperative microscopical view of the neurovascular conflict via a retrosigmoid approach. b Initial view of the dolichoectatic artery loop above the trigeminal nerve. c Delicate removal of the artery showing an imprint in the trigeminal nerve, suggesting chronic nerve compression. d Final view with small pieces of Dacron and Teflon isolating the nerve from the artery
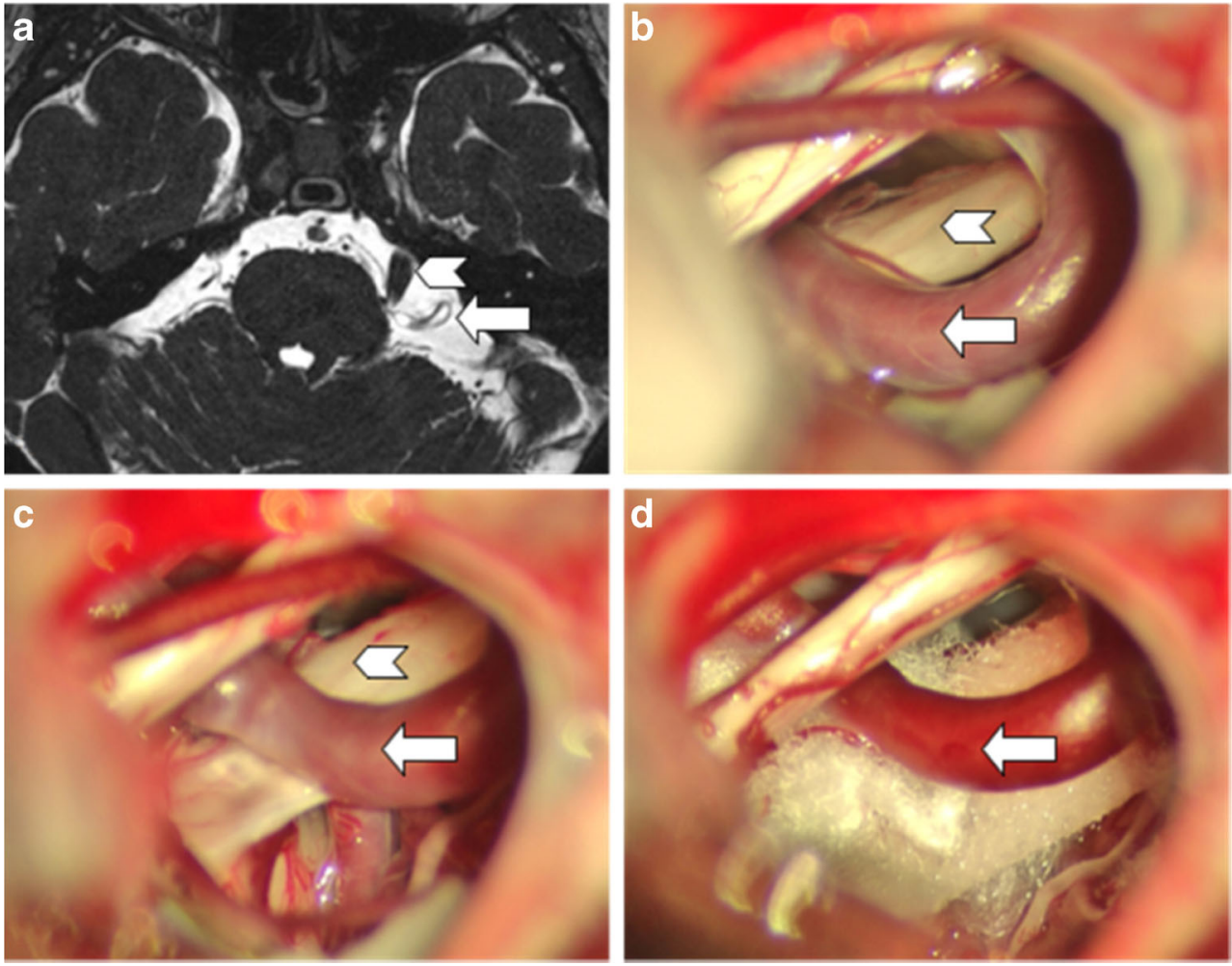

asymmetry and hemodynamic factors, the vertebral artery and vertebrobasilar junction can be in conflict with the trigeminal nerve more often on the left than on the right side [4]. It has even been suggested that in some cases, left-sided vertebrobasilar compression might contribute to medullary compression, leading to hypertension and atherosclerotic modifications [25].

\section{Imaging diagnosis}

Diagnosing trigeminal nerve compression is a central step before even proposing microsurgical decompression, based on brain MRI with 3D-FIESTA (T2-weighted MRI) and 3D-FSPGR, 3D-TOF or angio-MRI (contrast-enhanced T1weighted MRI). The first sequence gives detailed images of the cranial nerves and vascular structures contrasted with CSF. The others show vascular structures in hypersignal and therefore differentiate the vessels from the cranial nerves [5, 20, 26-28]. Compressions of the trigeminal nerve can usually be seen on axial view after reconstruction based on native imaging [29]. The correlation study between imaging data and intraoperative anatomical findings showed a sensitivity of MRI of $97 \%$ and a specificity of $100 \%$. In addition, it can specify the type and the degree of the compression [27, 28]. A dolichoectatic artery is defined by a diameter $>4.5 \mathrm{~mm}$ at any location along its course. If the basilar top is above the plane of the suprasellar cistern or if any portion is lateral to the clivus or dorsum sellae, elongation is considered to be present [30].
A compression involving a dolichoectatic vertebrobasilar artery was diagnosed on preoperative MRI in all cases reported in the literature as in ours. However, it is interesting to mention that in our cases, brain MRI was initially reported as normal, before the conflict was highlighted by a second exam performed by a trained neuroradiologist. Thus, vasculonervous conflict at the origin of essential trigeminal neuralgia is currently underdiagnosed due to the low quality of MRI, the lack of experience of radiologists, and the small size of the compression, especially in case of unusual location.

In 25 to $50 \%$ of patients, the vessel presses on the TREZ rather than on the nerve itself, which is only stretched away by the conflict [2]. In our cases, the dolichoectatic basilar artery mainly touched the TREZ or only the proximal portion of trigeminal nerve. Therefore, expert neuroradiological and neurosurgical advices are required before any definitive conclusion is drawn on the diagnosis of trigeminal neuralgia secondary to vasculonervous conflict.

\section{Treatment and technique of microsurgical decompression}

When a vasculonervous conflict is highlighted by brain MRI and the pharmacological treatment is not effective or not well tolerated, surgical decompression should be considered. Thus, surgical decompression is a second-line therapeutic strategy, along with other less invasive but less effective techniques such as thermocoagulation of Gasser ganglion, balloon compression, or radiosurgery. The classical microsurgical 
technique of decompression has been first described by Jannetta in 1967 [31] and then frequently modified [25, 31]. The objective of this procedure is to isolate the nerve from the vessel, by accessing the area of the compression through a suboccipital approach and placing a piece of material between the vessel and the nerve.

When the artery involved is a dolichoectatic vertebrobasilar artery, the usual procedure is technically more difficult and has to be adapted. Dolichoectatic arteries are atherosclerotic, tortuous, voluminous, stiff, and therefore almost impossible to shift from their original position. It is also frequent to find small arterial divisions that keep the main artery in its position. Instead of being shifted away from trigeminal nerve, the artery has to be isolated, for instance with pieces of Dacron or Teflon. The stiffer the vessel, the higher the risk of damaging the nerve or causing the migration of micro-emboli.

When the vertebrobasilar artery is involved, it can be associated with compression by other vessels in $74 \%$ of cases [4]. A common finding is an upward elevation of the TREZ by the vertebrobasilar artery, forcing it to impinge on the superior cerebellar artery or a rostral vein so that the nerve was ultimately compressed by a "vessel sandwich" [4]. We found this situation in two of our cases: the offending vessel was the dolichoectatic basilar artery with other compression by the superior cerebellar artery.

When multiple compressions are identified, all of them must be relieved during the surgery, as it is not possible to determine which one is causing the pain. This situation shows similarities with the case of hemifacial spasm, in which each compression is responsible for a part of the nervous disorder and has to be treated as such [32]. In surgical decompression of facial nerve, nervous activity can be monitored during the operation by electrophysiological testing [33], which is less commonly used in case of essential trigeminal neuralgia.

\section{Surgical results}

Microvascular decompression immediately relieves pain in $90 \%$ of cases and remains efficient after 15 years in $75 \%$ of cases [2]. The specific efficacy of the procedure in the case of dolichoectatic basilar arteries has not been evaluated. Overall, neurological complications of microvascular decompression are hypoesthesia (0-10\%), hearing impairment $(0.8-4.5 \%)$, ataxia $(0.2-2.7 \%)$, facial palsy $(0-1 \%)$, and diplopia secondary to sixth nerve palsy $(0.5-1 \%)$ [34]. CSF leakage occurs in $2-17 \%$ and is usually transient.

In the literature, the rate of adverse events is higher in case of vertebrobasilar artery compression, regarding hypoesthesia (41\%), diplopia (23\%), or hearing impairment (13\%), with only isolated cases of facial palsy, facial spasm, paresthesia, and mild ataxia. All these symptoms were sometimes irreversible, excepting diplopia which was always described as transient. In our cases, one patient had transient sixth nerve palsy without diplopia, transient facial palsy, and hypoesthesia, and one had mild persistent ataxia and mild diplopia. None of them had CSF leakage or other general complication.

The higher rate of neurological complications in the case of compression by a vertebrobasilar artery dolichoectasia may be explained by the stiffness and size of the vessel, which makes it more difficult to remove without damaging the surrounding structures. Thus, this type of compression is definitively technically more complex than compression by other vessels.

\section{Conclusion}

Vascular compression is a frequent and treatable cause of essential trigeminal neuralgia. Even in the rare and complex case of a dolichoectatic vertebrobasilar artery, microsurgical decompression is an effective therapeutic option for patients who do not respond to medication. Preoperative MRI of good quality is mandatory to correctly identify the neurovascular conflicts and should be interpreted by an experienced radiologist or neurosurgeon before ruling out the possibility of a surgical cure.

Author's contributions CA acquired, analyzed the data, and drafted the work.

JPL revised the work critically.

CLG designed the work and revised it critically.

All authors approved the final submitted version.

Compliance with ethical standards This research received no specific grant from any funding agency in the public, commercial, or not-forprofit sectors.

The authors declare no conflict of interest.

This retrospective case reports meet local ethical rules (French law Jardé 2012-300).

The patients have been informed that anonymous data would be used for publication and consented.

\section{References}

1. Sindou M, Keravel Y, Szapiro J, Abdennebi B (1987) Traitement neurochirurgical de la névralgie trigéminale. Abord direct ou méthode percutanée ? Neurochirurgie 33:89-111

2. Sindou M, Leston JM, Le Guerinel C, Keravel Y (2009) Traitement de la névralgie trigéminale par décompression vasculaire microchirurgicale. Neurochirurgie avril;55(2):185-196

3. Bonafé A. Conflits neurovasculaires de l'angle ponto-cérébelleux. /data/revues/02210363/00810006/694/ [Internet]. 2008 Mar 20 [cited 2014 May 11]; Available from: http://www.em-consulte. com/en/article/122933

4. Linskey ME, Jho HD, Jannetta PJ (1994 Jul) Microvascular decompression for trigeminal neuralgia caused by vertebrobasilar compression. J Neurosurg 81(1):1-9

5. Park K-J, Kondziolka D, Kano H, Berkowitz O, Ahmed SF, Liu X et al (2012 Jan) Outcomes of gamma knife surgery for trigeminal 
neuralgia secondary to vertebrobasilar ectasia. J Neurosurg 116(1): 73-81

6. Alcalá-Cerra G, Gutiérrez-Paternina JJ, Niño-Hernández LM, Moscote-Salazar LR, Polo Torres C, Sabogal BR (2011 Sep) Brain stem compression preceded by trigeminal neuralgia in a patient with vertebro-basilar and bilateral carotid dolichoectasia. Bol Asoc Médica P R 103(3):34-37

7. Faure J, Raybaud C, Argenson C, Salamon G (1971 Nov) The arterial relationships of the occipital foramen. Neurochirurgie 17(6):459-468

8. García De Sola R, Escosa Bagé M (2001 Apr) Microvascular decompression of trigeminal neuralgia caused by vertebrobasilar dolichoectasia. Rev Neurol 16;32(8):742-745

9. Goel A, Shah A (2009 Dec) Trigeminal neuralgia in the presence of ectatic basilar artery and basilar invagination: treatment by foramen magnum decompression. J Neurosurg 111(6):1220-1222

10. Gressot LV, Hassaneen W, Fox BD, Mitchell BD, Tatsui CE, Ehni BL et al (2012 Jun) Surgical treatment for combined hemifacial spasm and atypical trigeminal neuralgia caused by a tortuous basilar artery. Case report and review of the literature. J Neurosurg Sci 56(2):151-154

11. Harsh GR 4th, Wilson CB, Hieshima GB, Dillon WP (1991 Jun) Magnetic resonance imaging of vertebrobasilar ectasia in tic convulsif. Case report. J Neurosurg 74(6):999-1003

12. Ishii A, Kubota Y, Okamoto S, Matsuoka G, Yato S, Hori T, et al. Electrical neurocoagulation may be effective for intractable trigeminal neuralgia caused by vertebrobasilar dolichoectasia.

13. Kraemer JL, Pereira Filho A, de David A, de Faria G, de B M (2006 Mar) Vertebrobasilar dolichoectasia as a cause of trigeminal neuralgia: the role of microvascular decompression. Case report Arq Neuropsiquiatr 64(1):128-131

14. Lantéri-Minet M (1999 Feb) Physiopathology of neuropathic pain syndromes. Therapie 54(1):117-120

15. Lin C-F, Chen H-H, Hernesniemi J, Lee C-C, Liao C-H, Chen S-C et al (2012 Sep) An easy adjustable method of ectatic vertebrobasilar artery transposition for microvascular decompression. Clin Neurol Neurosurg 114(7):951-956

16. Ma X, Sun X, Yao J, Ni S, Gong J, Wang J et al (2013 Oct) Clinical analysis of trigeminal neuralgia caused by vertebrobasilar dolichoectasia. Neurosurg Rev 36(4):573-577 discussion 577-8

17. Miyazaki S, Fukushima T, Tamagawa T, Morita A (1987 Aug) Trigeminal neuralgia due to compression of the trigeminal root by a basilar artery trunk. Report of 45 cases. Neurol Med Chir (Tokyo) 27(8):742-748

18. Noma N, Kobayashi A, Kamo H, Imamura Y (2009 Sep) Trigeminal neuralgia due to vertebrobasilar dolichoectasia: three case reports. Oral Surg Oral Med Oral Pathol Oral Radiol Endod 108(3): e50-e55

19. Yang X-S, Li S-T, Zhong J, Zhu J, Du Q, Zhou Q-M et al (2012 May) Microvascular decompression on patients with trigeminal neuralgia caused by ectatic vertebrobasilar artery complex: technique notes. Acta Neurochir 154(5):793-797 discussion 797
20. Campos WK, Guasti AA, da Silva BF, Guasti JA (2012) Trigeminal Neuralgia due to Vertebrobasilar Dolichoectasia. Case Rep Neurol Med 2012:367304

21. Zhong J, Zhu J, Sun H, Dou NN, Wang YN, Ying TT, Xia L, Liu MX, Tao B, Li ST (2014) Microvascular decompression surgery: surgical principles and technical nuances based on 4000 cases. Neurol Res 36:882-893

22. Katusic S, Beard CM, Bergstralh E, Kurland LT (1990 Jan) Incidence and clinical features of trigeminal neuralgia, Rochester, Minnesota, 1945-1984. Ann Neurol 27(1):89-95

23. Meckel JF, Jourdan A-J-L. Manuel d'anatomie générale, descriptive et pathologique; 1825.

24. Stopford JSB (1916 Jan) The arteries of the pons and medulla oblongata. J Anat Physiol 50(Pt 2):131-164

25. Jannetta PJ (1985 Aug) Microsurgical management of trigeminal neuralgia. Arch Neurol 42(8):800

26. Anderson VC, Berryhill PC, Sandquist MA, Ciaverella DP, Nesbit GM, Burchiel KJ (2006 Apr) High-resolution three-dimensional magnetic resonance angiography and three-dimensional spoiled gradient-recalled imaging in the evaluation of neurovascular compression in patients with trigeminal neuralgia: a double-blind pilot study. Neurosurgery 58(4):666-673 discussion 666-73

27. Leal PRL, Froment J-C, Sindou M (2010 Feb) MRI sequences for detection of neurovascular conflicts in patients with trigeminal neuralgia and predictive value for characterization of the conflict (particularly degree of vascular compression). Neurochirurgie 56(1): 43-49

28. Sindou, P.R.L. Lea, J.-C. Froment. Valeur prédictive de l'IRM pour la détection et la caractérisation de la compression vasculaire dans les syndromes d'hyperactivité des nerfs crâniens (trijumeau et facial). Neurochirurgie. :178-80.

29. Tamraz J, Outin C, Secca MF, Soussi B. Principes d'imagerie par résonance magnétique de la tête, de la base du crâne et du rachis: Approche anatomo-clinique et guide d'interprétation. Springer; 2004. $748 \mathrm{p}$

30. Ubogu EE, Zaidat OO (2004 Jan) Vertebrobasilar dolichoectasia diagnosed by magnetic resonance angiography and risk of stroke and death: a cohort study. J Neurol Neurosurg Psychiatry 75(1):2226

31. Jannetta PJ (2007 Jul) Arterial compression of the trigeminal nerve at the pons in patients with trigeminal neuralgia. 1967. J Neurosurg 107(1):216-219

32. Jannetta PJ, Abbasy M, Maroon JC, Ramos FM, Albin MS (1977 Sep) Etiology and definitive microsurgical treatment of hemifacial spasm. Operative techniques and results in 47 patients. J Neurosurg 47(3):321-328

33. Lefaucheur J-P, Neves DO, Vial C (2013 Oct) [Electrophysiological monitoring of cranial motor nerves (V, VII, IX, X, XI, XII)]. Neurochirurgie. 2009 Apr;55(2):136-41. Neurosurg Rev 36(4): 657-660 discussion 660

34. Sweet WH (1988 Dec) Percutaneous methods for the treatment of trigeminal neuralgia and other faciocephalic pain; comparison with microvascular decompression. Semin Neurol 8(4):272-279 